\title{
Optimising the management of Pinus sylvestris L. stand under risk of fire in Catalonia (north-east of Spain)
}

\author{
José Ramón GonZÁLEZ ${ }^{\mathrm{a} *}$, Timo PUKKALA ${ }^{\mathrm{b}}$, Marc PALAHÍa \\ ${ }^{a}$ Centre Tecnològic Forestal de Catalunya, Pujada del seminari s/n, 25280, Solsona, Spain \\ ${ }^{b}$ University of Joensuu, Faculty of Forestry, PO Box 111, 80101 Joensuu, Finland
}

(Received 6 December 2004; accepted 29 April 2005)

\begin{abstract}
The paper introduces the risk of fire as part of a stand management optimisation problem for even-aged Pinus sylvestris L. stands in Spain. The study used a simulation-optimisation system, SPINE, to examine the effect of risk of fire on the optimal stand management schedule when maximising soil expectation value (SEV). The simulation sub-system includes a deterministic stand growth and yield simulator based on individual-tree growth and mortality models. The simulator was modified to include stochastic fire occurrence. The simulation subsystem was combined with a non-linear optimisation algorithm to find the optimal management schedule. Five different fire probabilities were analysed $(0,0.5,1,2$ and 5\% five-year fire probabilities). In most calculations, the probability of fire was assumed to be constant over the whole rotation, but an analysis was also conducted in which the probability depended on management and the stage of stand development. The results were computed for discounting rates of 1,2 and 3\%, site indexes of 17, 24 and $30 \mathrm{~m}$ (dominant height at 100 years), and 0 to 3 thinnings. The effects of reforestation cost, salvage possibility and regeneration lag were also studied. Increased fire probability caused 15 to 35 years reductions in the optimal rotation length, and also decreased soil expectation value. The effect of fire risk on the timing and intensity of thinnings was less systematic when a constant fire risk was assumed. When fire risk depended on stand structure, increased risk level led to earlier and heavier low thinnings.
\end{abstract}

scots pine / stochastic optimisation / forest fires / non-linear optimisation

Résumé - Optimisation de la gestion des peuplements de Pinus sylvestris L. soumis aux risques d'incendie en Catalogne (nord-est de l'Espagne). Le manuscrit aborde le risque d'incendie comme une composante du problème de l'optimisation de la gestion des peuplements équiennes de pin sylvestre en Espagne. L'étude utilise un système de simulation-optimisation, SPINE, pour examiner l'effet du risque d'incendie sur le planning de la gestion optimale des peuplements quand on maximalise la valeur espérée du sol (SEV). Le sous-système de simulation inclue un simulateur déterministe de croissance et de production basé sur des modèles de croissance d'arbres individuels et de mortalité. Le simulateur a été modifié pour inclure l'occurrence stochastique des incendies. Le sous-système de simulation était combiné avec un algorithme d'optimisation non-linéaire pour trouver le planning optimal de gestion. Cinq différentes probabilités d'incendie ont été analysées $(0,0,5,1,2$ et $5 \% 5$ ans de probabilités d'incendie). Dans la plupart des calculs, la probabilité d'incendie était supposée être constante sur toute la rotation mais il a aussi été mené une analyse dans laquelle la probabilité dépendait de la gestion et du stade de développement du peuplement. Les résultats ont été calculés pour des taux dégressifs de 1,2 et $3 \%$, site index de 17, 24 et $30 \mathrm{~m}$ (hauteur dominante à 100 ans) et de 0 à 3 éclaircies. Les effets du coût de régénération, la possibilité de récupération et le retard de la régénération ont aussi été étudiés. L'accroissement de la probabilité d'incendie entraîne une réduction de 15 à 35 ans dans la longueur de la rotation optimale et diminue aussi SEV. L'effet du risque d'incendie sur le rythme et l'intensité des éclaircies était moins systématique quand on suppose un risque constant. Lorsque le risque d'incendie dépend de la structure du peuplement, l'accroissement du niveau de risque conduit à des éclaircies par le bas précoces et fortes.

pin sylvestre / optimisation stochastique / feux de forêt / optimisation on linéaire

\section{INTRODUCTION}

Fire is the main cause of forest destruction in the countries of the Mediterranean basin. About 50000 fires sweep through an average of 500000 hectares (1\% of the forest area) of Mediterranean forest each year, causing enormous economic and ecological damage as well as loss of human life [37]. From 1985 to 1995 an average of ca. 3\% of the forest area was destroyed in Portugal, Spain and southern Italy [28]. The problem is becoming increasingly serious. The number of fires and the area burned was greater in the 1980s and particularly the 1990s in comparison with previous decades [1]. Despite better firefighting tools such as aeroplanes, helicopters and the exponential growth of costs on wildfire extinction, forest fires are far from being effectively controlled and remain a very serious menace in the northern Mediterranean sub-region [14]. In the Catalonia region (Spain) with an average of 12000 ha burnt per year in the 1990s, forest fires are perceived by society as the main environmental problem [29].

\footnotetext{
* Corresponding author: jr.gonzalez@ctfc.es
} 
Therefore, more emphasis needs to be placed on methods for risk assessment, fire danger rating, modelling fire behaviour, and on fire-related silvicultural treatments and forest planning approaches. Sustainable management of Mediterranean forest calls for the integration of the risk of forest fires in the decisionmaking process of forestry. In this context, the stand level offers the first meaningful level of decision making where the risk of fire can be considered.

The effect of risk of fire on economically optimal forest management strategies had already been examined in several studies in the United States and Canada in the 1980s [5, 15, 24, 25, 27]. However, these studies only evaluated the effect of the risk of fires on the optimal rotation age of the stand. In all these studies thinnings were ignored and risk was considered as constant or age-dependent. Routledge [27] and Martell [15], for instance, used a discrete time framework, whereas Reed [24] used a continuous time frame, and Reed and Errico [25] developed "fire adjusted volume-rotation curves" to solve the problem graphically. Later on Caulfield [5] modified Martell's [15] rotation model using stochastic dominance analysis to incorporate risk aversion on the optimal rotation decision.

Recently, several studies have examined the effect of risk of various hazards on forest management (e.g., [8, 9, 17, 30]). In a study about the optimal stand management under risk of windthrow destruction, Thorsen and Helles [30] divided the risk into exogenous or endogenous to the decision of the owner or manager. They called the risk endogenous to the manager's decision when the forest manager or owner can control the level of risk to which a stand is exposed through stand treatments and stand characteristics. Exogenous risk refers to factors that the forest owner cannot control, such as climate, features of surrounding areas, and anthropogenic factors.

Stochastic simulation or models offer a way to incorporate the risk aspects in forest management. For example, Möykkynen et al. [17] developed a stochastic simulation model to predict the development of a Norway spruce stand exposed to the risk of infection by Heterobasidion annosum. The model was then used with a non-linear optimisation algorithm to find the optimal management for the stand. Dieter [8] applied Monte Carlo modelling techniques to estimate the optimal rotation length when the objective was maximise the land expectation value of spruce and beech stands under risk of windthrow in Germany.

The simultaneous determination of optimal thinning policy and rotation age under uncertainty has been investigated by many researchers. Solving efficiently the problem of the optimal combination of number, timing and intensity of thinnings, and rotation length requires a growth and yield model and a simulation program that can predict forest stand development under any set of management parameters [19]. Optimisation techniques can aid in the search of a stand management schedule that maximises a given objective variable. Combined simulation and optimisation techniques have been widely used in many countries for calculating optimal silvicultural regimes. Among the most popular optimisation methods are dynamic programming and non-linear programming. Dynamic programming has proved very successful in solving problems based on stand-level growth models, but there are some shortcomings when individual-tree level growth models are used
[36]. Non-linear programming methods with individual-tree models have gained considerable popularity in stand management optimisation in even-aged stands [12, 17, 19, 26, 33-35] and uneven-aged stands $[3,12,31]$, the last study using individual-tree models for $P$. sylvestris and $P$. nigra in Catalonia [32]. In Valsta [36] a detailed review of prior research on standlevel optimisation is available.

At low altitudes the Catalonian Scots pine stands are usually dense and even-aged [18]. These stands are treated with low thinnings (removing suppressed trees) or mixed thinnings (removing also some co-dominant trees), and regenerated by a shelterwood system. The shelterwood system has a 20 -year regeneration period with a remaining stand basal area of 12 to $15 \mathrm{~m}^{2} \mathrm{ha}^{-1}$. Also a seed tree system with 30 to 40 parent trees per hectare is used. The parent trees are removed when regeneration is considered satisfactory [18].

In this study we use a simulation-optimisation system, SPINE [19], to examine the effect of risk of fire on the optimal even-aged management of Scots pine (Pinus sylvestris L.) stands in Catalonia when maximizing soil expectation value (SEV). It is assumed that the stand is regenerated with a shelterwood method. To facilitate the analysis, the originally deterministic simulation model of SPINE was made stochastic, the stochasticity arising from fires.

The effect of the level of a constant fire risk on the optimal stand management was analysed with varying site index, discounting rate and number of thinnings. It was assumed that fire risk is due to the surroundings of the stand, which remain similar for the whole rotation. The effects of some "uncertain parameters" - namely, post-fire regeneration costs, regeneration lag and salvage of timber after fire - were also studied. Finally, stand management was optimised with an assumption that the probability of fire depends on the management and stage of development of the stand.

\section{MATERIALS AND METHODS}

\subsection{Simulation-optimisation system}

The stand-level management support system, SPINE, presented in Palahí and Pukkala [19] was used to find the optimal stand management schedule under risk of fire. The system consists of a stand growth and yield simulator based on the individual-tree growth and mortality models developed by Palahí et al. [20] and an optimisation algorithm, which finds the optimal management schedule for a given objective function (Fig. 1). The system was modified to include stochastic fire occurrence. The objective function value that was passed to the optimisation algorithm was changed from a point-value into the mean of a user-defined number of repeated stochastic outcomes. A similar method was used by Pukkala and Miina [23] to include risks associated with tree growth and timber prices, and preferences of the decision maker into multi-objective optimisation of stand management.

The simulation-optimisation system is able to find the optimal timing and intensity of thinnings and the optimal time to commence regenerative cuts. The decision variables were thinning times, expressed as years since stand establishment or previous thinning, and the remaining stand basal area after each thinning. The management schedule for different fire occurrence probabilities and for three different site indexes (dominant heights of 17, 24 and $30 \mathrm{~m}$ at 100 years) was optimised using SEV as the objective function. 


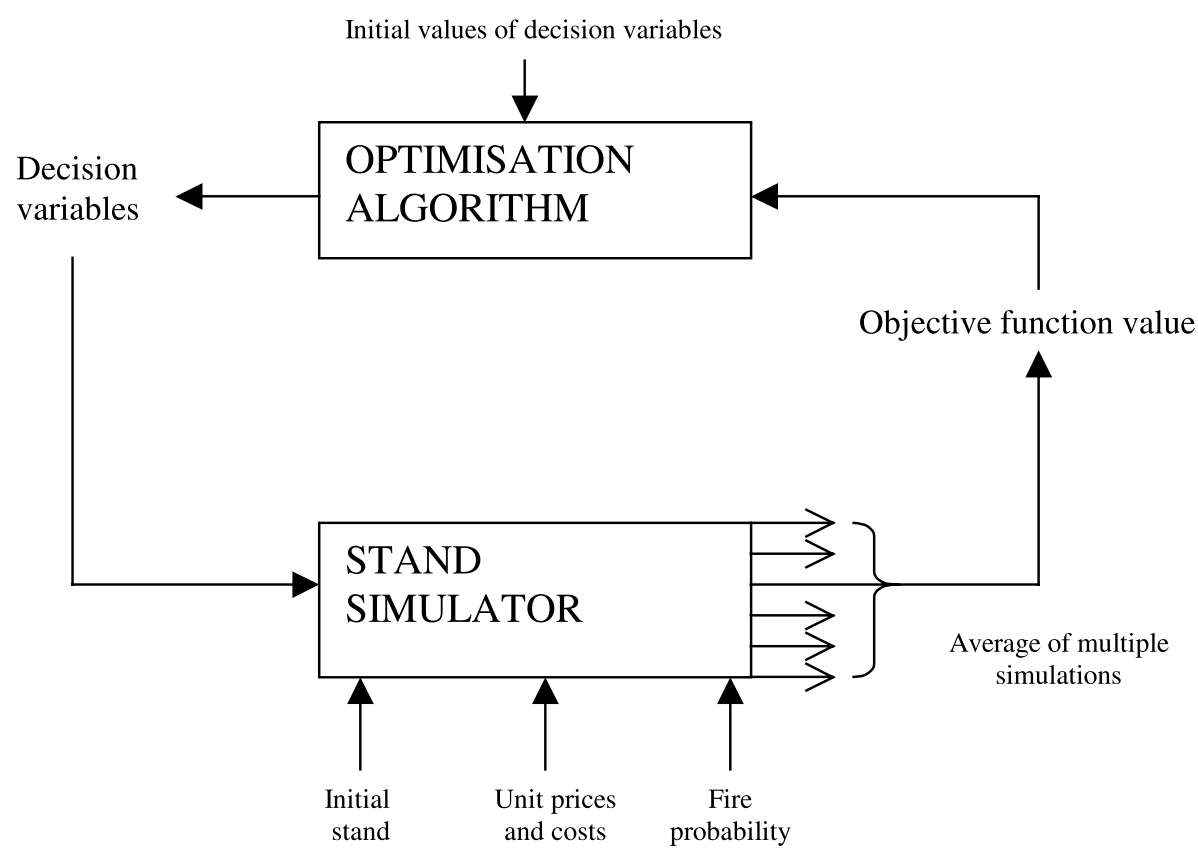

Figure 1. Structure of the stochastic simulation-optimisation system.

\subsection{Initial stand}

To initialise a simulation, the SPINE system requires the tree diameters of a plot, or the frequencies (number of trees per hectare) of different diameter classes. In addition, the stand age and the site index (dominant height at 100 years) of the forest stand are needed. The initial stand data used in this study came from plots measured during the Second Spanish National Inventory of 1991 in the province of Girona (northeast Spain), and they represented poor, medium and good site fertility for even-aged $P$. sylvestris stands (Tab. I). The same plots were used by Palahí and Pukkala [19] to analyse the optimal stand management in deterministic conditions. Like in the earlier study, it was assumed that a pre-commercial thinning had been conducted in all three initial stands.

\subsection{Simulation of growth}

The simulation system used a set of models for P. sylvestris [19] consisting of a dominant height model [21], an individual-tree diameter growth model, an individual tree height model, and a survival function to simulate stand development. The simulation of one fiveyear time step consisted of the following steps:

- For each tree, increase age by 5 years and add the five-year diameter increment to the diameter, using:

$$
\begin{aligned}
i d 5= & 4.1786-0.0070 \times d b h-8.0476 \times \frac{1}{d b h}+0.6945 \times \frac{d b h}{T} \\
& -0.0042 \times B A L-1.1092 \times \ln (G)+0.0764 \times S I
\end{aligned}
$$

where $i d 5$ is future diameter growth ( $\mathrm{cm}$ per $5 \mathrm{y}) ; d b h$ is diameter at breast height $(\mathrm{cm}), B A L$ is competition index measuring the total basal area of trees larger than the subject tree $\left(\mathrm{m}^{2} \mathrm{ha}^{-1}\right) ; T, G$ and $S I$ are stand age $(\mathrm{y})$, basal area $\left(\mathrm{m}^{2} \mathrm{ha}^{-1}\right)$ and site index $(\mathrm{m})$ at an index age of $100 \mathrm{y}$, respectively.
Table I. Characteristics of the study stands.

\begin{tabular}{lcccc}
\hline Plot & Hdom & $T$ & SI & $N$ \\
\hline 17 & 5.8 & 24 & 17 & 2228 \\
24 & 10.7 & 25 & 24 & 1934 \\
30 & 12 & 19 & 30 & 2069 \\
\hline
\end{tabular}

Hdom: dominant height; $T$ : stand age (years); SI: site index (Hdom at $100 \mathrm{y}) ; N$ : number of trees per hectare.

- Multiply the frequency of each tree (number of trees per hectare that a tree represents) by the five-year survival probability. The survival probability is calculated by equation (2).

$$
P(\text { survive })=\frac{1}{1+\exp \left(-\left(3.954-0.035 \times B A L+2.297 \times\left(\frac{d b h}{T}\right)\right)\right)}
$$

- Calculate the self-thinning limit (Eq. (3)). If the limit is exceeded after tree frequencies have been multiplied by the survival probability, then remove trees until the self-thinning limit is reached, starting with the trees with the lowest survival probability (Eq. (2)).

$$
\log \left(N_{\max }\right)=5.2060-1.8150 \times \log (D)+0.0212 \times S I
$$

where $N_{\max }$ is the highest possible number of trees per hectare, and $D$ is the mean square diameter $(\mathrm{cm})$. The mean square diameter is calculated from $D=\sqrt{40000 / \tau} \times G / N$. In equation (3), "log" is the base10 logarithm.

- Calculate stand dominant height from the site index and incremented stand age using equation (4), and calculate the dominant diameter from incremented tree diameters. 


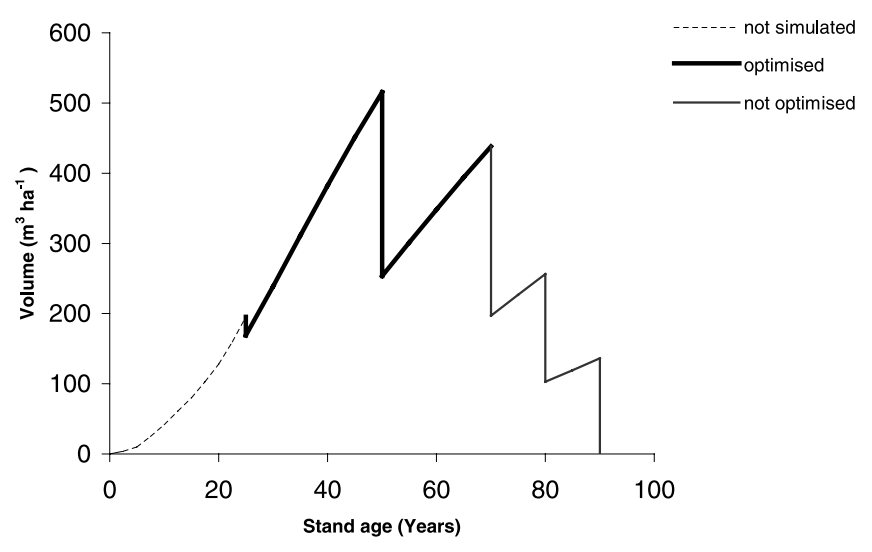

Figure 2. Simulation of a management schedule with two commercial thinnings (thick solid line) and three regenerative cuts (thin solid line) with the SPINE system. A pre-commercial thinning is supposed to have happened in the pre-simulation period (dashed line) even if it is not represented in this graphic. The period represented by the thick line was optimised in this study.

$H_{d o m}=\frac{T^{2}}{\left[18.6269+T \times\left[\frac{100}{S I}-0.03119 \times 100-\frac{18.6269}{100}+0.03119 \times T\right]\right]}$

where $H_{d o m}$ is dominant height at age $T$.

- Calculate tree heights using equation (5).

$H=1.3+\left(H_{d o m^{-}}-1.3\right) \times\left(\frac{d b h}{D_{d o m}}\right)^{\left(0.5546-0.3317 \times\left(\frac{d b h}{D_{d o m}}\right)-0.0015 \times T\right)}$

where $H$ is tree height (m) and $D_{d o m}$ is dominant diameter $(\mathrm{cm})$ of the stand.

The tree volumes are calculated using the formula developed by Pita Carpenter [22]:

$$
v=-28.34+2.16 \times h+16.59 \times d^{2}+2.794 \times d^{2} \times h
$$

where $v$ is tree volume in $\mathrm{dm}^{3}, h$ is tree height in $\mathrm{m}$ and $d$ is $d b h$ in $\mathrm{dm}$. This formula is based partly on the same permanent sample plots that were used to develop the tree growth and mortality models used in the stand simulator.

\subsection{Simulation of thinnings and regenerative cuts}

The SPINE system allows the simulation of thinnings and regenerative cuts (Fig. 2). However, thinning treatments must be restricted to thinnings from below since the growth simulation is driven by the dominant height development. When a thinning is simulated, the program removes half of the thinned basal area equally from all diameter classes, and the other half as a low thinning [19]. In SPINE the simulation of regenerative cuttings is conducted by mimicking the uniform shelterwood method, which includes three successive cuts during the 20 last years of the rotation [19]. To simulate a management regime, the number of thinnings and the following decision variables (DVs) should be specified:
For a thinning: stand age when the first thinning occurs; years since previous thinning for the other thinnings; remaining basal area.

For the final cutting: years since the last thinning to the first regenerative cut.

Figure 2 shows the simulation of the stand level development indicating the optimised and fixed management parameters under deterministic conditions.

\subsection{Fire occurrence}

It was assumed that the growing stock was destroyed when fire occurred. After fire, the stand was assumed to regenerate immediately. Different fire probabilities were used to examine the effect of fire frequency on optimal stand management. Fire probabilities during a fiveyear time step were set at $0,0.5,1,2$ and $5 \%$, and the probabilities were assumed to remain constant over the whole simulation period (independent of stand age and stage of development). These probabilities were applied stochastically for every five-year simulation step. If the stand was not burned during a five-year simulation step, it continued its development and a new five-year simulation step was begun. If a fire occurred during a simulation step, its exact year was generated (a random number between 0 and 5) and the simulation of stand development began again from a zero-year-old stand. The simulation continued until the stand accomplished a full rotation without burning (Fig. 3). To calculate the SEV, it was assumed that the simulated period is followed by similar periods to infinity.

\subsection{Economic parameters}

Natural regeneration was assumed after regenerative cuts and after fire. The costs and incomes were equal to the ones used by Palahí and Pukkala [19]. The tending cost was considered always to be $600 € /$ ha, based on data provided by the Forest Centre of Catalonia. The tending year was estimated based on a study by Montero et al. [16] who suggested pre-commercial thinning at stand age 15 to 25 years depending on stand growth rate (site index) as follows:

$$
t=35-0.677 \times S I
$$

where $t$ is tending year and $S I$ the site index.

Logging costs were based on the unit price tariffs offorestry activities (Cuadro de precios unitarios de la actividad forestal) provided by the Asociación y Colegio de Ingenieros de Montes [2], and on a study by Montero et al. [16]. From these data, a model giving the total logging cost as a function of tree size has been developed by Palahí et al. [20]:

$$
c=[0.0564-0.003 \times \ln (d b h)]
$$

where $c$ is the logging cost in euros $/ \mathrm{m}^{3}$ and $d b h$ is the diameter at breast height in $\mathrm{cm}$. An additional 6 euros $/ \mathrm{m}^{3}$ was added to cover the removal of cuttings residuals, plus 3.6 euros/ha as an entry cost (including authorisation and marking of trees to be logged), plus an extra 9 euros/ ha as an annual management and administration cost.

A road-side timber price of $48 € / \mathrm{m}^{3}$ was assumed for diameter class $27.5 \mathrm{~cm}$ based on a study by Díaz Balteiro and Prieto Rodríguez [7]. A correction index was used for trees larger than $34 \mathrm{~cm}$ dbh dependent of diameter [16]. The index assumed an increase in the proportion of timber for veneer wood, and that there was a price increase for veneer wood. The price for small diameter classes came from data collected by the Forest Technology Centre of Catalonia. All these data were smoothed to give a road-side price function of the tree diameter

$$
p=-23.21+13.61 \times \sqrt{D}
$$




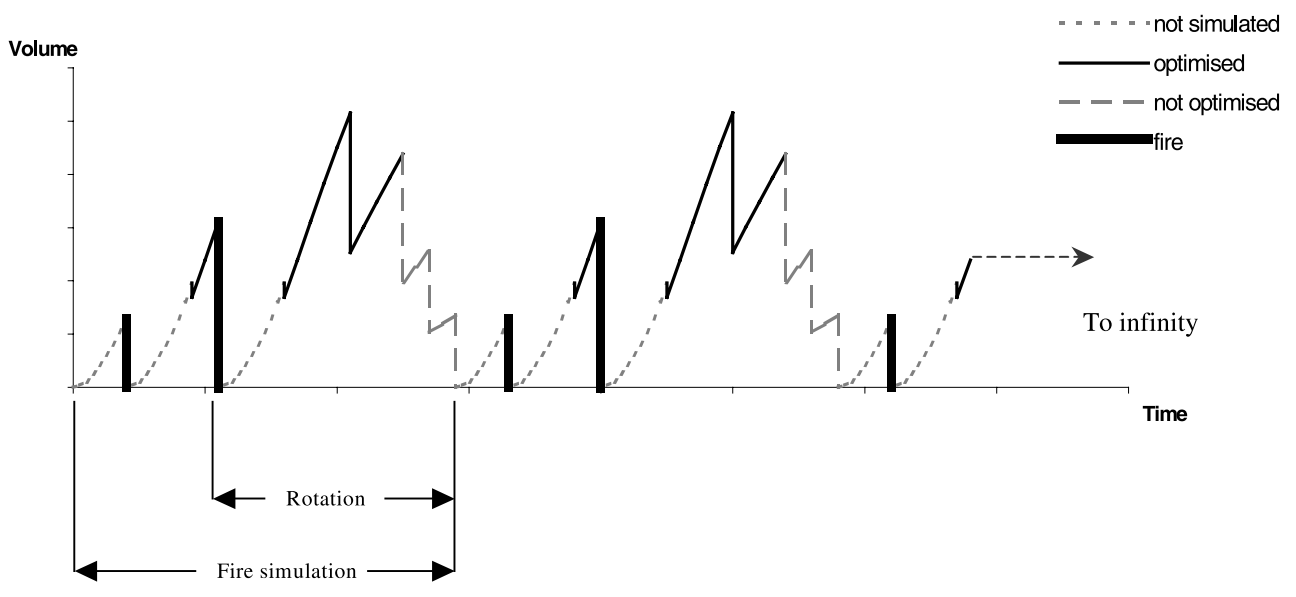

Figure 3. Stand development simulation (Fire simulation) with stochastic fires. Simulation was stopped once a full rotation was obtained. To calculate $S E V$ it was assumed that the period indicated as "Fire simulation" is repeated to infinity.

where $p$ is a road-side timber price $\left(€ / \mathrm{m}^{3}\right)$ and $D$ is $d b h(\mathrm{~cm})$ for trees smaller than $65 \mathrm{~cm}$ in diameter, and $65 \mathrm{~cm}$ otherwise. After the stand was burned it was supposed to be destroyed and no price was given to the timber.

\subsection{Optimisation}

The optimisation algorithm of Hooke and Jeeves [13] was used to find the optimal management schedule for Scots pine stands. This algorithm operates using two search modes: exploratory search and pattern search. The exploratory search examines points around the base point (a vector of $D V \mathrm{~s}$ ) in the direction of the co-ordinate axes $(D V \mathrm{~s})$. The pattern search moves the base point in the direction defined by the previous base point and the best point of exploratory search. The optimal management schedule for a given number of thinnings is eventually found, after repeating a search-process as many times as defined by a convergence criterion (for more details see [4]).

Because the optimisation algorithm did not necessarily converge to the global optimum, all optimisations were repeated 11 times, each run starting from the best of 100 random combinations of $D V$ s, except the first one, which started from a user-defined starting point. The random values of the $D V$ s were uniformly distributed over a specified range:

- Years from regeneration to the first thinning: 5-80 y;

- Interval of latter cuttings: 5-40 y;

- Remaining basal area in a thinning: 5-40 $\mathrm{m}^{2} \mathrm{ha}^{-1}$.

These ranges only affected the preliminary random search and the initial step size of direct search; the direct search was allowed to go outside these ranges. The initial step-size in the direct search was 0.1 times the user-specified range. The step size was reduced gradually, and the search stopped when the step size was less than 0.01 times the initial step (i.e., 0.001 times the range). Because the risk of fire was a stochastic process, the simulation was repeated 500 times with every combination of $D V \mathrm{~s}$ to yield the distribution of $S E V \mathrm{~s}$ corresponding to a set of decision variables. The expected $S E V$ was computed as the mean of the 500 outcomes.

Discounting rate and site index were varied under varying fire probabilities in order to observe the combined effect of risk of fire and these changing variables on the optimal management. In addition, sensibility analyses were conducted for different numbers of thinnings $(0,1$, 2 and 3 thinnings) and a set of "uncertain parameters":
- A reforestation cost of $1500 € /$ ha was added in the beginning of each rotation (based on Espelta et al. [10]);

- A post-fire stochastic salvage percentage uniformly distributed between 0 and $100 \%$ of the growing stock value was assumed; or

- A stochastically distributed regeneration lag ranging from 0 to 20 years was used.

The last set of optimisations analysed the effect of managementdependent and stand-structure-dependent fire risk. A recent fire probability model of González et al. [11] was used to calculate the probability of fire as a function of stand characteristics. These analyses were conducted for two-thinning regimes, site index $24 \mathrm{~m}$, and $2 \%$ discounting rate. The 12-year probability given by the model was converted into 5-year probability. The model prediction depends of mean diameter, standard deviation of diameters, stand basal area, proportion of hardwood, and elevation of the site. The elevation was assumed to be $700 \mathrm{~m}$ a.s.l., which according to the model is the upper-limit of the high-risk area. The model cannot be used in very young stands $(d b h<$ $7.5 \mathrm{~cm}$ ). The 5-year fire probability of stands younger than the initial stand was assumed to be $5 \%$, which corresponds to typical model predictions for young pine stands in risky areas. To analyse the effect of variation in the overall risk level (for instance due to elevation and the consequent change in humidity) the model prediction and the probability used for young stands were multiplied by $0,0.5,1$, and 2 .

\section{RESULTS}

\subsection{Effect of fire risk with different discounting rates}

The effect of fire risk under different discount rates showed a clear trend for site index $24 \mathrm{~m}$ and 2 thinnings (Fig. 4): the higher the fire risk and the discounting rate, the shorter was the optimal rotation and the lower was the $S E V$. The rotation varied from $105 \mathrm{y}$ under no risk of fire and $1 \%$ discount rate, to $59 \mathrm{y}$ with $5 \%$ fire probability and 2 to $3 \%$ discounting rates. The rotation length did not fall below $59 \mathrm{y}$, probably due to the low price of small size timber and high harvesting cost per cubic meter of such reduced rotations. The timing of thinnings was somewhat earlier at higher fire risks, but otherwise no clear tendencies 

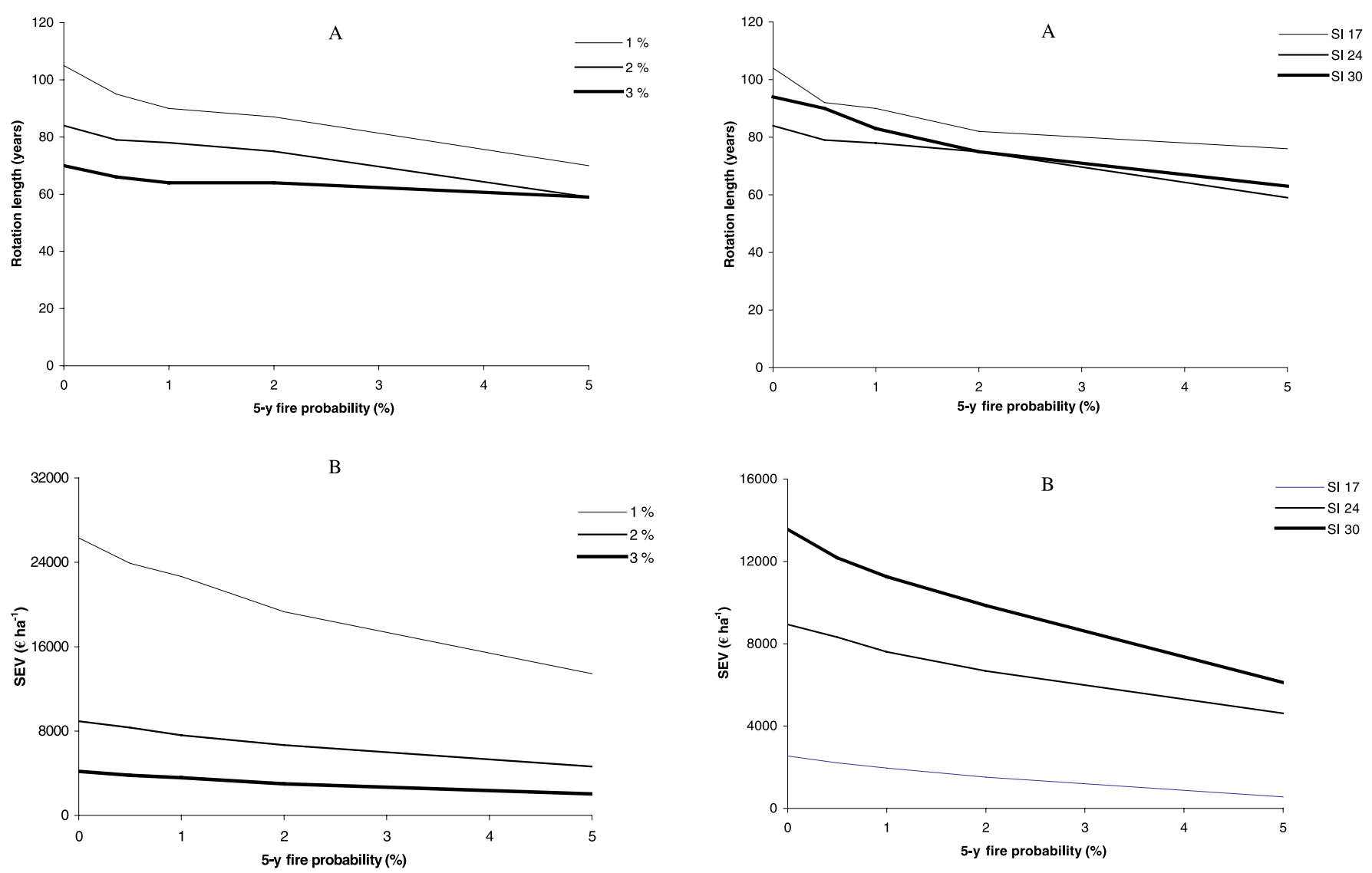

Figure 4. Optimal rotation length (A) and soil expectation value (SEV) (B) on site index $24 \mathrm{~m}$ with 2 thinnings, when maximising soil expectation value with 1,2 and 3 percent discounting rate and varying fire probability.

were observed in the other $D V \mathrm{~s}$. For all discounting rates the $S E V$ decreased by almost $50 \%$ when the five-year fire risk increased from 0 to $5 \%$.

\subsection{Effect of fire risk on different sites}

When different site indexes $(17,24$ and $30 \mathrm{~m})$ were analysed with 2 thinnings and a discounting rate of $2 \%$, the optimal rotation and $S E V$ decreased for all sites when the probability of fire increased. However, the effect of site index on the rotation length was not systematic. The rotations were longest for site index $17 \mathrm{~m}$ but site index 24 did not have longer rotations than site index 30 (Fig. 5). The lack of a clearer trend might be explained by differences in the initial characteristics (diameter distributions) of the plots. The $S E V$ decreased on site index $30 \mathrm{~m}$ by almost $50 \%$ when the probability of fire increased from 0 to $5 \%$, and by more than $400 \%$ on site index $17 \mathrm{~m}$.

\subsection{Effect of number of thinnings}

The effect of the probability of fire for different numbers of thinnings was studied with a discounting rate of $2 \%$ on site index of $24 \mathrm{~m}$. The optimisation results suggested an increment

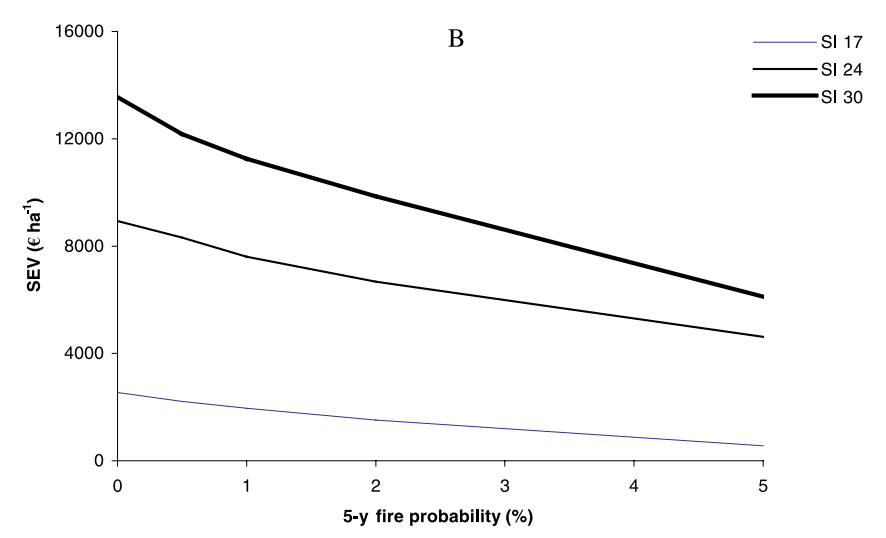

Figure 5. Optimal rotation length (A) and soil expectation value $(S E V)($ B) on site index 17,24 and $30 \mathrm{~m}$ (dominant height at 100 years), with 2 thinnings and $2 \%$ discounting rate when maximising soil expectation value under different fire probabilities.

in the rotation length under more intensive management scenarios (Fig. 6). The $S E V$ showed small variations between different numbers of thinnings, especially under high risk of fire. Under no fire risk, increasing the number of thinnings seemed a good strategy to increase the objective function value, but at $5 \%$ fire probability the differences in $S E V$ were very small. Irrespective of the number of thinnings, increasing fire probability decreased rotation length and $S E V$.

\subsection{Effect of uncertain parameters}

The next part of the study consisted of comparisons between a control solution (optimum for $2 \%$ discount rate, site index $24 \mathrm{~m}, 2$ thinnings, with no regeneration cost or lag and no salvage) and scenarios where there was variation in an uncertain parameter (regeneration cost, regeneration lag and salvage possibility). Change in the above-mentioned parameters did not result in rotation lengths very different from the control solution (Fig. 7). The use of a regeneration cost increased the rotation length under high probabilities of fires. The effects of uncertain parameters on $S E V$ were clearer. A salvage possibility increased the $S E V$ under all fire probabilities while regeneration lag and regeneration cost reduced the $S E V$. 

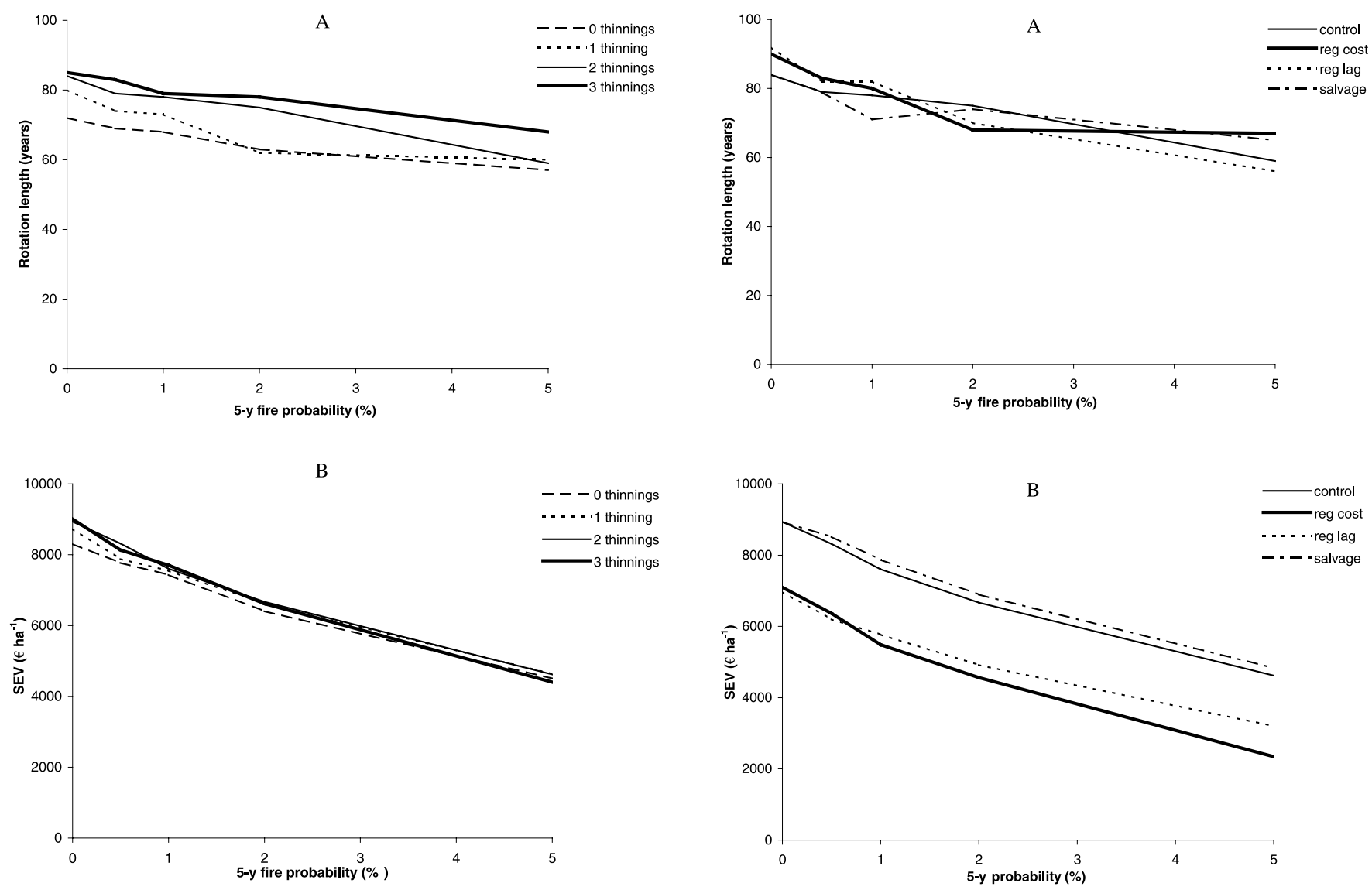

Figure 6. Optimal rotation length $(\mathbf{A})$ and soil expectation value $(S E V)(\mathbf{B})$ on site index $24 \mathrm{~m}$ with $2 \%$ discounting rate when maximising soil expectation value under different fire probabilities and number of thinnings $(0,1,2$ and 3$)$.

\subsection{Results with endogenous risk}

Optimisations with the risk model support the earlier conclusions about the effect of the level of risk on optimal rotation length (Fig. 8). Also the $S E V$ was strongly correlated with the factor by which the model prediction was multiplied: multipliers $0,0.5,1$ and 2 resulted in soil expectation values of 13600 , 8522,6265 and $3689 € /$ ha, respectively with a $2 \%$ discounting rate. When an endogenous fire probability was assumed, the effect of the level of risk on thinnings was clearer than with exogenous risk. When there is a risk of fire, and it depends on stand structure according to the model of Gonzalez et al. [11], the stand should be treated with a low thinning immediately. The higher is the overall risk level the heavier are the low thinnings.

\section{DISCUSSION}

The inclusion of a stochastic fire occurrence model into the stand simulation-optimisation system enables the forest manager to consider the risk of fire in stand-level forest management. The method described in this paper allows the manager

Figure 7. Optimal rotation length (A) and soil expectation value $(S E V)(\mathbf{B})$ on site index $24 \mathrm{~m}$ with $2 \%$ discounting rate and 2 thinnings when maximising soil expectation value under different assumptions about regeneration cost, regeneration lag and salvage possibility.

to simultaneously find the optimal values for many decision variables that describe a stand management schedule (timing and intensity of thinnings and time to commence regenerative cuts). Even when the risk of fire was assumed to be constant over the rotation, our approach is different from previous studies, which have mainly been focused on the effect of risk of fire on the optimal rotation length [5, 15, 24, 25, 27]. This is because our analyses took into account the fact that thinnings modify the effect of fire risk on optimal rotation length by allowing part of the harvest to be collected earlier, and with a lower risk of loosing it.

The used fire probabilities (0-5\%) cover a realistic range of fire risk levels for $P$. sylvestris in Catalonia. The fire statistics in the region show an average five-year fire probability of $0.17 \%$ for pure $P$. sylvestris stands, and $4.87 \%$ for all pine stands. These observations led us to use the range from 0 to $5 \%$, considering the high variability in the fire risk of individual stands. In most optimisations the risk of fire was considered to be exogenous, which means that the possible relationship between stand age, thinnings and fire probability was omitted. This kind of optimisation is justified in cases where the risk mainly arises from areas located outside the forest stand; the ignition point is elsewhere and the fire enters the stand by 


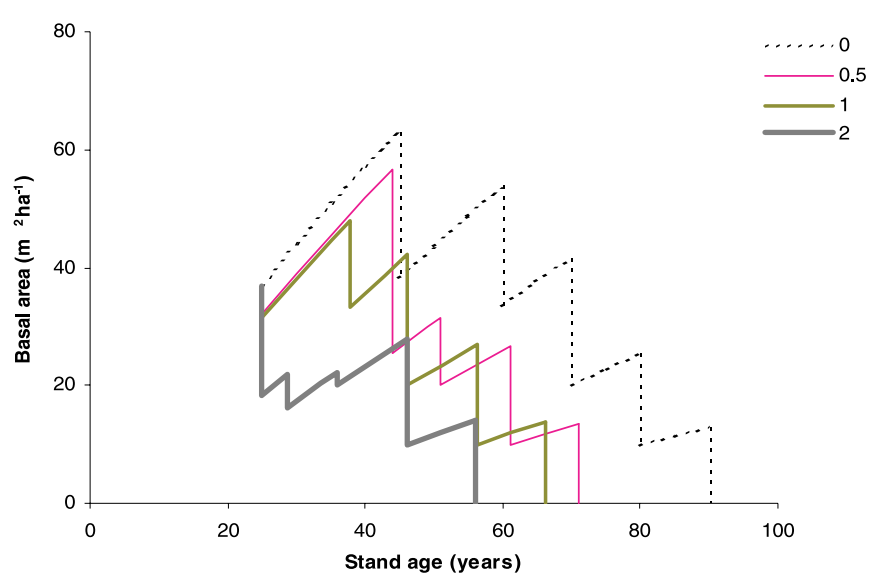

Figure 8. Development of stand basal area in the optimal management schedule for site $24 \mathrm{~m}, 2$ thinnings, and $2 \%$ discounting rate, when the prediction of the fire risk model is multiplied by $0,0.5,1$, or 2 .

spreading from outside. A rather small Scots pine stand with more or less permanent surroundings in terms of fire factors (surrounding stands, roads, settlements) corresponds to this situation.

In optimisation with constant fire risk, no clear effect of the risk level on the timing and intensity of thinnings was observed. There were variation in the results, but the fact that many combinations of cutting times and thinning intensities are nearly equally good [19], and the consequent possibility that many of the optima may in fact be local optima, makes it difficult to discern trends in the thinnings. Therefore, the analysis of the results was focused on the rotation length and SEV of the optimal management strategies under risk of fire, even if the timing and intensity of thinnings affect both of them.

However, it is also justified to assume that fire risk is endogenous, i.e., it depends on management and the stage of stand development. This assumption is the most justified in a large forest all of which is managed in the same way. When optimisations were made with endogenous fire risk, the effect of fire risk on thinnings was clearer. The higher is the overall risk level of the region, the earlier and heavier are the low thinnings. Most probably also the type of thinnings depends on the risk of fire, but it could not be optimised with the simulation-optimisation system employed in this study. Because low thinning decreases the vertical continuity of fuels and therefore the probability that a ground fire changes into a damaging crown fire, it may be optimal to remove all low canopy layers in risky areas.

The optimisations showed clear trends on SEV and optimal rotation as a function of fire risk. The analysis conducted in this study indicates that shorter rotations should be used under increasing fire probability in all the study cases, which agrees with previous studies [5, 15, 24, 25, 27]. The rotation length decreases more with increasing discounting rate. This result agrees with Reed [24] who compared the effect of risk of fire by adding a premium to the discount rate in a risk-free environment. The $S E V$ was rather insensitive to the number of thinnings under different fire risk scenarios, especially under high fire probabilities. A salvage possibility increased $S E V$ and rota- tion length under high-risk scenarios. This result is in accordance with Routledge [27] and Reed and Errico [25]. Additional regeneration cost and regeneration lag decreased $S E V$ with all fire probabilities, but most of all when a regeneration cost was applied with high fire probability. This result agrees with the results found by Reed and Errico [25].

Timber management planning can be divided [6] into two distinct categories: (1) situations in which planning can be done independently for each stand; and (2) situations in which the planning must be co-ordinated for all stands in the forest. When fire risk is considered in practical forest management planning the division between these two categories gets ambiguous and fire risk analysis made for single stands are less useful. Instead, a forest level analysis is needed to estimate the stands' fire probability, which is partly determined by conditions in the surrounding area. To develop a practical system for forest management planning under the risk of fire, a deeper understanding of the relationships between fire occurrence probability and surrounding conditions, site, age, stand management and fire prevention activities is needed. Furthermore, salvage timber price estimations and post-fire regeneration models are crucial factors for efficiently including the risk of fire in forest management decision-making. However, the principal aim of the study was not to estimate the probability of fire but to observe the effect of the risk of fire on the optimal management of $P$. sylvestris stands.

Acknowledgements: This study has been funded by the Ministerio de Educación y Ciencia (Spain) through the project AGL2004-00382/ FOR. The study is conducted within the MEDFOREX centre coordinated by the CTFC. We are grateful to Mr. Tim Green for the linguistic revision of the manuscript.

\section{REFERENCES}

[1] Alexandrian D., Esnault F., Calabri G., Forest fires in the Mediterranean area, Unasylva 157, 1999.

[2] Asociación y colegio de Ingenieros de Montes, Cuadro de precios unitarios de la actividad forestal, Madrid, 2000.

[3] Bare B.B., Opalach D., Optimising species composition in unevenaged forest stands, For. Sci. 33 (1987) 958-970.

[4] Bazaraa M.S., Shetty C.M., Nonlinear programming: Theory and algorithms, Wiley, New York, 1979.

[5] Caulfield J.P., A Stochastic Efficiency Approach for Determining the Economic Rotation of a Forest Stand, For. Sci. 34 (1988) 441457.

[6] Clutter J.L., Forston J.C., Piennar L.V., Brister B.H., Bailey R.L., Timber management - a quantitative approach, Wiley, New York, 1983.

[7] Díaz Balteiro L., Prieto Rodríguez A., Modelos de planificación forestal basados en la programación lineal. Aplicación al monte "Pinar de Navafría" (Segovia), Investig. Agr. Recur. For. 8 (1999) 63-93.

[8] Dieter M., Land expectation values for spruce and beech calculated with Monte Carlo Modelling Techniques, For. Pol. Econ. 2 (2001) 157-166.

[9] Englin J., Baxall P., Hauer G., An empirical examination of optimal rotations in a multiple-use forest in the presence of fire risk, $\mathrm{J}$. Agric. Res. Econ. 25 (2000) 14-27. 
[10] Espelta J.M., Retana J., Habrouk A., An economic and ecological multi-criteria evaluation of reforestation methods to recover burned Pinus nigra forest in NE Spain, For. Ecol. Manage. 180 (2003) 185-198.

[11] González J.R., Palahí M., Trasobares A., Pukkala T., A fire risk model for forest stands in Catalonia, Manuscript, 2005.

[12] Haight R.G., Monserud R.A., Optimizing any-aged management of mixed-species stands: II. Effects of decision criteria, For. Sci. 36 (1990) 125-144.

[13] Hooke R., Jeeves T.A., "Direct search" solution of numerical and statistical problems, J. Assoc. Comput. Mach. 8 (1961) 212-229.

[14] Lanly J.P., Foresterie circumméditerranéenne et coopération internationale, C. R. Acad. Agric. France 83 (1997) 55-64.

[15] Martell D.L., The Optimal rotation of a flammable forest stand, Can. J. For. Res. 10 (1980) 30-34.

[16] Montero M., Rojo A., Del Rio M., Aspectos selvícolas y económicos de los pinares de Pinus sylvestris L. en el Sistema Central, procedings of the open seminar: "Explotación y conservación del monte mediterráneo: una apuesta para el futuro", Universidad de Málaga, Ronda, Malaga, 1996.

[17] Möykkynen T., Miina J., Pukkala T., Optimizing the management of a Picea abies stand under risk of butt rot, For. Path. 30 (2000) 65-76.

[18] Palahí M., Modelling the stand development and optimising the management of even-aged Scots pine forests in north-east Spain, Doctoral thesis at the University of Joensuu, Finland, 2002, 58 p. + App.

[19] Palahí M., Pukkala T., Optimising the management of Scots pine (Pinus sylvestris L.) stands in Spain based on individual-tree models, Ann. For. Sci. 60 (2003) 105-114.

[20] Palahí M., Pukkala T., Miina J., Montero G., Individual-tree growth and mortality models for Scots pine (Pinus sylvestris L.) in northeast Spain, Ann. For. Sci. 60 (2003) 1-10.

[21] Palahí M., Tomé M., Pukkala T., Trasobares A., Montero G., Site Index model for Scots pine (Pinus sylvestris $\mathrm{L}$.) in north-east Spain, For. Ecol. Manage. 187 (2003) 35-47.

[22] Pita Carpenter A., Tablas de cubicación por diámetros normales y alturas totales, Instituto Forestal de Investigaciones y Experiencias, Ministerio de Agricultura, Madrid, 1967.
[23] Pukkala T., Miina J., A method for stochastic multiobjective optimisation of stand management, For. Ecol. Manage. 98 (1997) 189203.

[24] Reed W.J., The effects of the risk of fire on the optimal rotation of a forest, J. Environ. Manage. 11 (1984) 180-190.

[25] Reed W.J., Errico D., Assessing the long-run yield of a forest stand subject to the risk of fire, Can. J. For. Res. 20 (1985) 961-969.

[26] Roise J.P., An approach for optimizing residual diameter class distributions when thinning even-aged stands, For. Sci. 32 (1986) 871-881.

[27] Routledge R.D., The effect of potential catastrophic mortality and other unpredictable events on optimal forest rotation policy, For. Sci. 26 (1980) 389-399.

[28] Scarascia-Mugnozza G., Oswald H., Piussi P., Radoglou K., Forests of the Mediterranean region: gaps in knowledge and research needs, For. Ecol. Manage. 132 (2000) 97-109.

[29] Tábara D., La percepció dels problemes del medi ambient, Beta Editorial, Barcelona, 1996.

[30] Thorsen B., Helles F., Optimal stand management with endogenous risk of sudden destruction, For. Ecol. Manage. 108 (1998) 287-299.

[31] Trasobares A., Pukkala T., Optimising the management of unevenaged Pinus sylvestris L. and Pinus nigra Arn. Mixed stands in Catalonia, north-east Spain, Ann. For. Sci. 61 (2004) 747-758.

[32] Trasobares A., Pukkala T., Miina J., Growth and yield model for uneven-aged mixtures of Pinus sylvestris L. and Pinus nigra Arn. in Catalonia, north-east Spain, Ann. For. Sci. 61 (2004) 9-24.

[33] Valsta L., Possibilities to optimize stand treatment based on individual trees, Scand. For. Econ. 29 (1987) 151-160.

[34] Valsta L., A comparison of numerical methods for optimizing even aged stand management, Can. J. For. Res. 20 (1990) 961-969.

[35] Valsta L., An optimization model for Norway spruce management based on individual-tree growth models, Acta For. Fenn. 232 (1992) $1-20$.

[36] Valsta L., Stand management optimization based on growth simulators, Research Notes Finnish Forest Research Institute 453 (1993) $51+81 \mathrm{p}$.

[37] Vélez R., Causes of forest fires in the Mediterranean Basin, EFI Proceedings 45 (2002) 35-42.

To access this journal online: www.edpsciences.org 